\title{
APLIKASI MODEL EPIDEMIK SEIAR-SEI PADA PENYEBARAN PENYAKIT MALARIA DENGAN INFEKSI ASIMTOMATIK DAN SUPER INFEKSI
}

\author{
Stella Maryana Belwawin *
}

\begin{abstract}
This aim of this study is to determine the point of equilibrium and analyze the stability of SEIAR-SEI model on malaria disease with asymptomatic infection, super infection and the effect of the mosquito's life cycle. This study also aim is to measure the sensitivity of the spread of malaria to the parameters of asymptomatic infections, the rate of treatment, and the rate of birth of mosquitoes through the magnitude of $\mathcal{R}_{0}$. The method in this research is deductively, through several stage, such as determination of disease-free equilibrium point and endemic equilibrium point, determination of basic reproduction number $\left(\mathcal{R}_{0}\right)$, analyze of the basic reproduction number sensitivity of the spread of malaria to the parameters of asymptomatic infections, the rate of treatment, and the rate of birth of mosquitoes. The endemic equilibrium point was obtained using rule of Descartes. The result show that the change in the value of parameter $\sigma, \theta$, and $s_{L}$ has effect on the basic reproduction number $\left(\mathcal{R}_{0}\right)$. Treatment factors in the human population influence the elimination of malaria in a population. Whereas asymptomatic infection factors and the birth rate of adult mosquitoes influence the increase in malaria infection.
\end{abstract}

Keywords: Malaria, asymptomatic infection, super infection, basic reproduction number, rule of descrates.

\begin{abstract}
Abstrak
Penelitian ini bertujuan menentukan titik keseimbangan dan menganalisis kestabilan dari model SEIAR_SEI pada penyakit malaria dengan pengaruh infeksi asimtomatik, super infeksi, dan siklus hidup nyamuk. Penelitian ini juga bertujuan mengukur tingkat sensitivitas penyebaran penyakit malaria terhadap parameter infeksi asimtomatik, laju pengobatan, serta laju kelahiran nyamuk.melalu besaran $\mathcal{R}_{0}$. Metode yang digunakan dalam penelitian ini adalah metode deduktif dengan langkah-langkah : menentukan titik keseimbangan bebas penyakit dan endemik dan menentukan bilangan reproduksi dasar $\left(\mathcal{R}_{0}\right)$. Analisis sensitivitas bilangan reproduksi dasar dilakukan terhadap parameter infeksi asimtomatik, pengobatan, dan laju kelahiran nyamuk. Tititk keseimbangan endemik diperoleh dengan aturan descrates. Hasil yang diperoleh menunjukkan parameter $\sigma, \theta$, dan $S_{L}$ berpengaruh terhadap bilangan reproduksi dasar $\left(\mathcal{R}_{0}\right)$. Faktor pengobatan berpengaruh terhadap eliminasi penyakit malaria. Sedangkan faktor infeksi asimtomatik dan laju kelahiran nyamuk dewasa berpengaruh terhadap peningkatan infeksi penyakit malaria.
\end{abstract}

Kata kunci: Malaria, Infeksi Asimtomatik, Super Infeksi, Bilangan Reproduksi Dasar, Aturan Descrates .

\section{Pendahuluan}

Malaria adalah penyakit yang disebabkan oleh infeksi protozoa yang disebut dengan Plasmodium. Penyakit ini ditularkan oleh nyamuk Anopheles betina dan sering muncul pada

* Program studi Magister Matematika Universitas Hassanuddin,

Email: smayabelwawin@ymail.com 
daerah tropis seperti Indonesia dan negara-negara di Asia lainnya, terutama di Indonesia bagian timur [4]. Secara matematika, penyebaran penyakit menular dapat dimodelkan untuk memprediksi penyebaran penularan penyakit malaria ke depan. Berdasarkan prediksi tersebut dapat dilakukan upaya pencegahan agar penyakit malaria dapat dieliminasi. Model Epidemik SEIR merupakan salah satu model yang dapat dipakai pada kasus malaria. Pada model ini populasi manusia dibagi menjadi empat kelas yaitu: S(Susceptible), E (Exposed), I (Infected) dan $R$ (Removed). Sedangkan pada populasi nyamuk terdiri dari 3 kompartemen yaitu: $S$ (Susceptible), E (Exposed), I (Infected). Penelitian terbaru oleh Bakary Traore dkk (2017) [5] yang meneliti tentang penularan malaria dengan struktur umur untuk vektor populasi. Peneliti menggunakan model epidemik SEIRS-SEI untuk mengkonstruksi dinamika penyebaran penyakit malaria dari nyamuk ke manusia. Liming Cai (2017) mengenalkan model malaria dengan kelas infeksi asimtomatik pada populasi manusia. Infeksi asimtomatik adalah infeksi penyakit yang tidak menunjukkan gejala. Penderita pembawa infeksi atau penyakit tidak mengalami gejala yang nyata. Infeksi asimtomatik juga disebut sebagai infeksi subklinis, atau infeksi diam secara klinis [3].

Berdasarkan penjelasan yang telah dipaparkan diatas, maka diketahui bahwa faktorfaktor penting dalam dinamika transmisi penyakit malaria adalah yang berkaitan tentang infeksi asimtomatik, superinfeksi dan siklus hidup nyamuk. Pada penelitian ini akan dilakukan pengembangan model dengan meninjau faktor-faktor penting dari model-model yang telah dikembangkan oleh Bakary Traore dan peneliti lainnya. Pemodelan akan meninjau kasus malaria asimtomatik dan superinfeksi pada populasi manusia serta siklus hidup nyamuk untuk memahami faktor-faktor penting dalam penyebaran penyakit malaria. Penelitian ini akan dituliskan dalam tesis dengan judul: "Aplikasi Model Epidemik SEIARSEI pada penyebaran penyakit malaria dengan infeksi asimtomatik dan superinfeksi “.

\section{Model Matematika}

Model SEIAR yang merupakan pengembangan dari model SEIR secara umum terbagi menjadi 4 kelas yaitu susceptible (S), exposed (E), Infected (I), dan recovered (R) (Jinhong dkk, 2014). Namun pada model penyakit malaria tersebut dikembangkan menjadi model SEIAR-SEI dengan 5 kelas pada populasi manusia yaitu : Susceptible $\left(S_{h}\right)$, Exposed $\left(E_{h}\right)$, Infected $\left(I_{h}\right)$, Asymtomatic Infected $\left(A_{h}\right)$, dan Recovered $\left(R_{h}\right)$ [1]. Sedangkan pada populasi nyamuk terdiri dari 5 kelas yaitu: Eggs $(E)$, Larva dan Pupa $(L)$, Susceptible $\left(S_{m}\right)$, Exposed $\left(E_{m}\right)$, Infected $\left(I_{m}\right)$ [5]. Total dari jumlah populasi manusia dan nyamuk dewasa diberikan masing-masing oleh :

$$
\begin{aligned}
& N_{h}(t)=S_{h}(t)+E_{h}(t)+I_{h}(t)+A_{h}(t)+R_{h}(t) \\
& A(t)=S_{m}(t)+E_{m}(t)+I_{m}(t)
\end{aligned}
$$

Berdasarkan kompartemen diatas maka model dapat ditulis dalam bentuk bentuk persamaan differensial sebagai berikut :

$$
\begin{aligned}
& \frac{d E(t)}{d t}=b\left(1-\frac{E(t)}{K_{E}}\right) A(t)-(s+d) E(t) \\
& \frac{d L(t)}{d t}=s\left(1-\frac{L(t)}{K_{L}}\right) E(t)-\left(s_{L}+d_{L}\right) L(t) \\
& \frac{d S_{h}(t)}{d t}=\Lambda_{h}+\gamma R_{h}(t)-\frac{\beta_{h} I_{m}(t)}{N_{h}(t)} S_{h}(t)-d_{h} S_{h}(t)+\theta r_{h} I h \\
& \frac{d E_{h}(t)}{d t}=\frac{\beta_{h} I_{m}(t)}{N_{h}(t)} S_{h}(t)-\left(d_{h}+\gamma_{e}\right) E_{h}(t) \\
& \frac{d I_{h}(t)}{d t}=\alpha \gamma_{e} E_{h}(t)+\frac{\rho \beta_{h} A_{h}(t) I_{m}(t)}{N_{h}(t)}-\left(d_{h}+d_{p}+r_{h}\right) I_{h}(t) \\
& \frac{d A_{h}(t)}{d t}=(1-\alpha) \gamma_{e} E_{h}(t)+(1-\theta) r_{h} I_{h}(t)-\frac{\rho \beta_{h} A_{h}(t) I_{m}(t)}{N_{h}(t)}-d_{h} A_{h}(t)
\end{aligned}
$$




\section{Stella Maryana Belwawin}

$\frac{d R_{h}(t)}{d t}=r_{h} I_{h}(t)-\left(d_{h}+\gamma\right) R_{h}(t)$

$\frac{d S_{m}(t)}{d t}=\mathrm{s}_{L} L(t)-\beta_{m}\left(\frac{I_{h}(t)+\sigma \mathrm{A}_{h}(t)+\eta R_{h}(t)}{N_{h}(t)}\right) S_{m}(t)-d_{m} S_{m}(t)$

$\frac{d E_{m}(t)}{d t}=\beta_{m}\left(\frac{I_{h}(t)+\sigma A_{h}(t)+\eta R_{h}(t)}{N_{h}(t)}\right) S_{m}(t)-\left(v_{m}+d_{m}\right) E_{m}(t)$

$\frac{d I_{m}(t)}{d t}=v_{m} E_{m}(t)-d_{m} I_{m}(t)$.

Dengan :

$\frac{d S_{h}(t)}{d t}$ menyatakan laju perubahan jumlah individu yang rentan malaria pada waktu t.

$\frac{d E_{h}(t)}{d t}$ menyatakan laju perubahan jumlah individu yang terpapar ke dalam masa inkubasi (exposed) pada waktu t.

$\frac{d I_{h}(t)}{d t}$ menyatakan laju perubahan jumlah individu yang sakit malaria pada waktu t.

$\frac{d A_{h}(t)}{d t}$ menyatakan laju perubahan jumlah individu yang terinfeksi namun tidak menunjukkan gejala pada waktu t.

$\frac{d R_{h}(t)}{d t}$ menyatakan perubahan individu yang sembuh pada waktu t.

$\frac{d S_{m}(t)}{d t}$ menyatakan laju perubahan jumlah nyamuk rentan terinfeksi penyakit malaria pada waktu t.

$\frac{d E_{m}(t)}{d t}$ menyatakan laju perubahan jumlah nyamuk yang mengalami masa inkubasi parasit penyakit malaria pada waktu t.

$\frac{d I_{m}(t)}{d t}$ menyatakan laju perubahan jumlah nyamuk terinfeksi penyakit malaria pada waktu t.

$\frac{d E(t)}{d t} \quad$ menyatakan laju perkembangbiakan telur nyamuk pada waktu $\mathrm{t}$.

$\frac{d L(t)}{d t} \quad$ menyatakan laju perubahan jumlah telur nyamuk menjadi larva pada waktu $\mathrm{t}$.

Variabel dan parameter yang digunakan disajikan pada Tabel 1 dan Tabel 2

Tabel 2. Variabel Pada Model Malaria SEIAR-SEI

\begin{tabular}{|c|l|}
\hline Variabel & \multicolumn{1}{|c|}{ Keterangan } \\
\hline$S_{h}$ & Jumlah Susceptible pada manusia \\
\hline$E_{h}$ & Jumlah Exposed pada manusia \\
\hline$I_{h}$ & Jumlah Infected pada manusia \\
\hline$A_{h}$ & Jumlah Asymptomatic Infected pada manusia \\
\hline$R_{h}$ & Jumlah Recover pada manusia \\
\hline$S_{m}$ & Jumlah Suceptible pada nyamuk \\
\hline$E_{m}$ & Jumlah Exposed pada nyamuk \\
\hline$I_{m}$ & Jumlah Infected pada nyamuk \\
\hline$E$ & Jumlah Telur nyamuk \\
\hline$L$ & Jumlah Larva nyamuk \\
\hline
\end{tabular}

Tabel 2. Parameter pada model malaria SEIAR - SEI

\begin{tabular}{|c|lc|}
\hline Parameter & & Keterangan \\
\hline$\Lambda_{h}$ & laju kelahiran manusia & \\
\hline
\end{tabular}


Stella Maryana Belwawin

\begin{tabular}{|c|l|}
\hline$\gamma$ & Konstanta laju hilangnya kekebalan tubuh pada manusia setelah sembuh \\
\hline$\alpha \gamma_{e}$ & laju perpindahan manusia terpapar ke manusia terinfeksi \\
\hline$(1-\alpha) \gamma_{e}$ & Probabilitas perpindahan dari Exposed ke kelas Asymptomatic Infected \\
\hline$\beta_{h}$ & Laju terjadinya infeksi ( tingkat gigitan nyamuk) pada manusia \\
\hline$\beta_{m}$ & $\begin{array}{l}\text { Laju terjadinya infeksi ( tingkat gigitan nyamuk sehat menggigit individu yang } \\
\text { terinfeksi malaria) }\end{array}$ \\
\hline$\eta$ & Proporsi infektifitas dari individu $\mathrm{R}_{h}$ yang sembuh pada nyamuk sehat. \\
\hline$\rho$ & $\begin{array}{l}\text { Konstanta laju super infeksi dari individu yang terinfeksi namun tidak } \\
\text { terdeteksi (asymptomatic infected). }\end{array}$ \\
\hline$\sigma$ & $\begin{array}{l}\text { Konstanta pengurangan atau peningkatan infektivitas dari individu } \\
\text { asimtomatik pada nyamuk yang sehat. }\end{array}$ \\
\hline$(1-\theta) r_{h}$ & laju perpindahan dari individu yang terinfeksi ke kelas asimtomatik \\
\hline$k_{h}$ & laju infeksi dari nyamuk ke manusia \\
\hline$d_{h}$ & laju kostan kematian manusia secara alami \\
\hline$r_{h}$ & Konstanta laju pemulihan manusia dari parasit malaria \\
\hline$s$ & laju perpindahan dari kelas telur nyamuk ke kelas larva \\
\hline$s_{L}$ & laju perubahan dari larva menjadi nyamuk dewasa \\
\hline$b$ & laju pembentukan telur nyamuk \\
\hline$d$ & laju kematian telur nyamuk \\
\hline$d_{L}$ & laju kematian telur nyamuk \\
\hline$s_{L}$ & laju kelahiran nyamuk dewasa \\
\hline$k_{m}$ & laju infeksi malaria dari manusia ke nyamuk \\
\hline$d_{m}$ & laju kostan kematian nyamuk secara alami \\
\hline$v_{m}$ & laju perpindahan nyamuk terpapar ke nyamuk terinfeksi \\
\hline
\end{tabular}

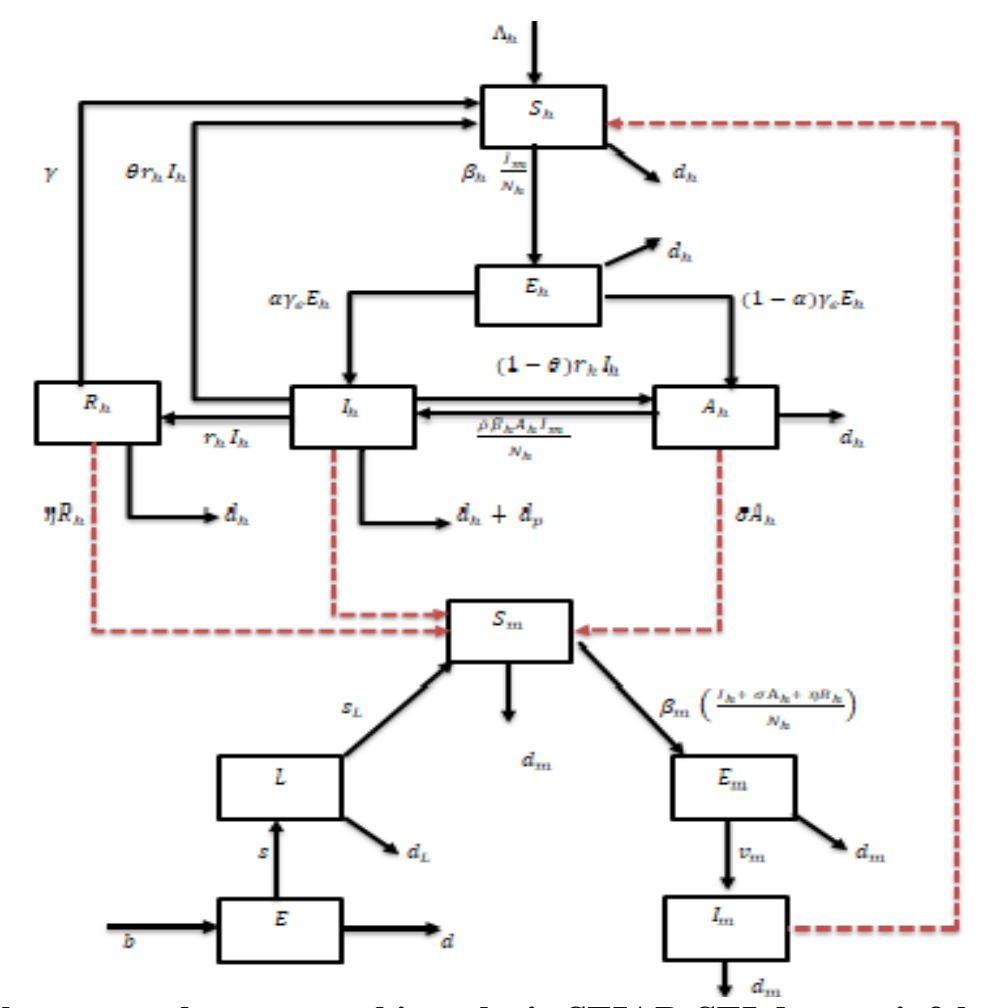

Gambar 1. Skema penularan penyakit malaria SEIAR-SEI dengan infeksi asimtomatik, superinfeksi dan siklus hidup nyamuk 
Pada penelitian sebelumnya, lihat [1], secara matematis diperoleh hasil bahwa penyakit malaria dapat ditularkan jika terjadi kontak antara nyamuk rentan dengan individu asimtomatik. Beberapa upaya yang dapat dilakukan untuk mencegah terjadinya wabah yaitu dengan melakukan pengobatan pada populasi manusia yang terinfeksi penyakit malaria. Pada penelitian ini akan dianalisis beberapa parameter yang mempengaruhi nilai reproduksi bilangan dasar $\left(\mathcal{R}_{0}\right)$.

\section{Hasil dan Pembahasan}

Pada bagian ini model (3) akan dianalisis dengan menentukan titik kesetimbangan bebas penyakit, titik keseimbangan endemik, bilangan reproduksi dasar dan kestabilan dari titik keseimbangan model SEIAR-SEI tersebut. Titik keseimbangan bebas penyakit merupakan keadaan saat penyakit menular tidak menyebar dalam suatu populasi dan terjadi pada saat $E_{h}=E_{m}=0$. Untuk $E_{h}=E_{m}=0$ maka diperoleh $I_{h}=A_{h}=I_{m}=R_{h}=0$. Substitusi $E_{h}=E_{m}=I_{h}=A_{h}=R_{h}=I_{m}=0$ sehingga diperoleh titik keseimbangan bebas penyakit :

$\Sigma_{0}=\left(E_{0}, L_{0}, A_{0}, S_{h_{0}}, E_{h_{0}}, I_{h_{0}}, A_{h_{0}}, R_{h_{0}}, E_{m_{0}}, I_{m_{0}}\right)=\left(0,0,0, \frac{\Lambda_{h}}{d_{h}}, 0,0,0,0,0,0\right)$

Menurut Diekmann dkk (1990) [2] $F V^{-1}$ adalah matriks generasi dari model maka bilangan reproduksi dasar (basic reproduction number) dinyatakan sebagai :

$$
\mathcal{R}_{0}=\rho\left(F V^{-1}\right)
$$

Dengan $\rho\left(F V^{-1}\right)$ merupakan spektral radius dari matriks $F V^{-1}$.

Spektral radius dari matriks next generation $F V^{-1}$ adalah :

$\pm \sqrt{\frac{\beta_{h} v_{m} \beta_{m} s_{L} K_{L} \gamma_{e} d_{h}\left(-\alpha c_{4} r_{h} \sigma \theta-\alpha c_{2} c_{4} \sigma+\alpha c_{3} \eta r_{h}+\alpha c_{4} r_{h} \sigma+\alpha c_{3} c_{4}+c_{2} c_{4} \sigma\right)}{d m^{2} \Lambda_{h} c_{1} c_{2} c_{3} c_{4} c_{5}}}$. Sehingga nilai bilangan reproduksi dasar yaitu :

$\mathcal{R}_{0}=\sqrt{\frac{\beta_{h} \beta_{m} v_{m} s_{L} K_{L} \gamma_{e} d_{h}\left(-\alpha c_{4} r_{h} \sigma \theta-\alpha \gamma c_{2} c_{4} \sigma+\alpha c_{3} \eta r_{h}+\alpha c_{4} r_{h} \sigma+\alpha c_{3} c_{4}+c_{2} c_{4} \sigma\right)}{d m^{2} \Lambda_{h} c_{1} c_{2} c_{3} c_{4} c_{5}}}$

Selanjutnya akan dianalisis dampak beberapa parameter terhadap bilangan reproduksi dasar yaitu :

1. $\theta$ yaitu laju pengobatan terhadap individu yang terinfeksi sehingga dapat berpindah ke kelas susceptible (rentan).

2. $\sigma$ laju pengurangan atau peningkatan infektivitas dari individu tanpa gelaja (asimtomatik) terhadap nyamuk yang rentan.

3. $\eta$ yaitu proporsi individu yang sembuh tetapi masih berpeluang menularkan parasit jika tergigit oleh nyamuk sehat.

4. $S_{L}$ yaitu laju kelahiran nyamuk dewasa dimana larva nyamuk berubah menjadi nyamuk dewasa.

Hasil yang diperoleh dari bentuk $\frac{\partial \mathcal{R}_{0}}{\partial \theta}>0$ pada kasus penyakit malaria menunjukkan bahwa peningkatan pengobatan yang diberikan akan sehingga terjadi kondisi bebas penyakit. Hasil yang diperoleh dari $\frac{\partial \mathcal{R}_{0}}{\partial \eta}<0$ juga menunjukkan bahwa peningkatan jumlah individu yang telah sembuh namun masih bisa menularkan penyakit pada kasus penyakit malaria akan berdampak pada peningkatan infeksi dalam populasi (penurunan nilai $\mathcal{R}_{0}$ ). Sedangkan hasil dari $\frac{\partial \mathcal{R}_{0}}{\partial \sigma}<0$ menunjukkan bahwa dengan adanya peningkatan infeksi malaria dari individu dengan infeksi asimtomatik berdampak pada peningkatan infeksi dalam populasi manusia dan populasi nyamuk (peningkatan nilai $\mathcal{R}_{0}$ ). Hasil dari $\frac{\partial \mathcal{R}_{0}}{\partial s_{L}}<0$ juga menunjukkan dengan adanya peningkatan laju kelahiran nyamuk dewasa pada populasi nyamuk akan berdampak pada peningkatan infeksi dalam kasus penyakit malaria (peningkatan nilai $\mathcal{R}_{0}$ ). 
Titik keseimbangan endemik merupakan keadaan saat penyakit menular menyebar dalam suatu populasi dan terjadi saat $E_{h}, E_{m}>0$. Untuk $E_{h}, E_{m}>0$ maka diperoleh $I_{h}, A_{h}, R_{h}>0$. Misalkan rata-rata laju infeksi pada populasi manusia adalah $k_{h}$ dan pada nyamuk adalah $k_{m}$ yang telah didefinisikan dengan persamaan :

$$
\begin{aligned}
k_{h}=\beta_{h} \frac{I_{m}}{N_{h}}, \text { dan } & \\
k_{m} & =\beta_{m}\left(\frac{I_{h}+\sigma \mathrm{A}_{h}+\eta R_{h}}{N_{h}(t)}\right)
\end{aligned}
$$

Setelah melakukan proses saling substitusi maka diperoleh titik keseimbangan endemik sebagai berikut :

$\Sigma_{2}=\left(S_{h_{2}}{ }^{*}, E_{h_{2}}{ }^{*}, I_{h_{2}}{ }^{*}, A_{h_{2}}{ }^{*}, R_{h_{2}}{ }^{*}, A_{2}{ }^{*}, E_{m_{2}}{ }^{*}, I_{m_{2}}{ }^{*}\right)$

(10)

dengan :

$S_{h_{2}}{ }^{*}=\frac{c_{1} c_{2} c_{4} \Lambda_{h}}{M}$,

$E_{h_{2}}^{*}=\frac{k_{h} c_{2} c_{4} \Lambda_{h}}{M}$,

$I_{h_{2}}{ }^{*}=\frac{k_{h} c_{4} \Lambda_{h}\left(\alpha \gamma_{e}+\rho k_{h} A_{11}\right)}{M}$,

$A_{h_{2}}{ }^{*}=\frac{k_{h} c_{2} c_{4} \Lambda_{h} A_{11}}{M}$,

$R_{h_{2}}{ }^{*}=\frac{r_{h} k_{h} \Lambda_{h}\left(\alpha \gamma_{e}+\rho k_{h} A_{11}\right)}{M}$,

$A_{2}{ }^{*}=\frac{s_{L} K_{L}}{d_{m}}$,

$E_{m_{2}}{ }^{*}=\frac{k_{m} s_{L} K_{L}}{d_{m}\left(c_{5}+v_{m} k_{m}\right)}$, dan

$I_{m_{2}}{ }^{*}=\frac{v_{m} k_{m} s_{L} K_{L}}{d_{m}^{2}\left(c_{5}+v_{m} k_{m}\right)}$

dengan syarat :

$A_{11}=\frac{(1-\alpha) c_{2} \gamma_{e}+(1-\theta) r_{h} \alpha \gamma_{e}}{c_{2}\left(\rho k_{h}+c_{3}\right)-\rho(1-\theta) r_{h} k_{h}}>0$

$M=c_{1} c_{2} c_{4}\left(k_{h}+d_{h}\right)-r_{h} k_{h}\left(\alpha \gamma_{e}+\rho k_{h} A_{11}\right)\left(\gamma+c_{4} \theta\right)>0$ atau $c_{1} c_{2} c_{4}\left(k_{h}+d_{h}\right)>0$.

\section{Kesimpulan}

Kesimpulan yang diperoleh dari penelitian ini adalah :

1. Titik keseimbangan bebas penyakit yang diperoleh dari model SEIAR-SEI pada penyakit malaria dengan pengaruh infeksi asimtomatik, super infeksi dan siklus hidup nyamuk adalah :

$\Sigma_{0}=\left(E_{0}, L_{0}, A_{0}, S_{h_{0}}, E_{h_{0}}, I_{h_{0}}, A_{h_{0}}, R_{h_{0}}, E_{m_{0}}, I_{m_{0}}\right)=\left(0,0,0, \frac{\Lambda_{h}}{d_{h}}, 0,0,0,0,0,0\right)$.

Titik keseimbangan endemik model SEIAR-SEI pada penyakit malaria dengan pengaruh infeksi asimtomatik, super infeksi dan siklus hidup nyamuk adalah :

$\Sigma_{2}=\left(S_{h_{2}}{ }^{*}, E_{h_{2}}{ }^{*}, I_{h_{2}}{ }^{*}, A_{h_{2}}{ }^{*}, R_{h_{2}}{ }^{*}, A_{2}{ }^{*}, E_{m_{2}}{ }^{*}, I_{m_{2}}{ }^{*}\right)$

dengan

$$
\begin{aligned}
& S_{h_{2}}{ }^{*}=\frac{c_{1} c_{2} c_{4} \Lambda_{h}}{M}, \\
& {E_{h_{2}}}^{*}=\frac{k_{h} c_{2} c_{4} \Lambda_{h}}{M}, \\
& I_{h_{2}}{ }^{*}=\frac{k_{h} c_{4} \Lambda_{h}\left(\alpha \gamma_{e}+\rho k_{h} A_{11}\right)}{M},
\end{aligned}
$$




$$
\begin{aligned}
& A_{h_{2}}{ }^{*}=\frac{k_{h} c_{2} c_{4} \Lambda_{h} A_{11}}{M}, \\
& R_{h_{2}}{ }^{*}=\frac{r_{h} k_{h} \Lambda_{h}\left(\alpha \gamma_{e}+\rho k_{h} A_{11}\right)}{M}, \\
& A_{2}{ }^{*}=\frac{s_{L} K_{L}}{d_{m}}, \\
& E_{m_{2}}{ }^{*}=\frac{k_{m} s_{L} K_{L}}{d_{m}\left(c_{5}+v_{m} k_{m}\right)}, \text { dan } \\
& I_{m_{2}}{ }^{*}=\frac{v_{m} k_{m} s_{L} K_{L}}{d_{m}^{2}\left(c_{5}+v_{m} k_{m}\right)} .
\end{aligned}
$$

Dengan syarat

$$
\begin{aligned}
& A_{11}=\frac{(1-\alpha) c_{2} \gamma_{e}+(1-\theta) r_{h} \alpha \gamma_{e}}{c_{2}\left(\rho k_{h}+c_{3}\right)-\rho(1-\theta) r_{h} k_{h}}>0, \text { dan } \\
& M=c_{1} c_{2} c_{4}\left(k_{h}+d_{h}\right)-r_{h} k_{h}\left(\alpha \gamma_{e}+\rho k_{h} A_{11}\right)\left(\gamma+c_{4} \theta\right)>0 \\
& \text { atau } c_{1} c_{2} c_{4}\left(k_{h}+d_{h}\right)>0
\end{aligned}
$$

2. Faktor infeksi asimtomatik pada populasi manusia $(\sigma)$ memiliki pengaruh terhadap perubahan nilai $\mathcal{R}_{0}$. Jika nilai $\sigma$ yang diberikan semakin besar maka nilai $\sigma$ juga semakin besar. Faktor superinfeksi tidak berpengaruh pada besaran $\mathcal{R}_{0}$ karena parameter superinfeksi $\rho$ tidak terdapat dalam $\mathcal{R}_{0}$. Sedangkan faktor pengobatan $\theta$ yang diberikan kepada individu dengan infeksi simtomatik sehingga dapat berpindah ke kelas infeksi asimtomatik dan individu rentan, menyebabkan perubahan terhadap nilai $\mathcal{R}_{0}$. Semakin besar nilai $\theta$ yang diberikan maka nilai $\mathcal{R}_{0}$ semakin kecil.

\section{Daftar Pustaka}

[1]. Cai Liming dkk,, 2017. Optimal Control of a Malaria Model with Asymptomatic Class and Superinfection, doi/ 10.1016/j.mbs.2017.03.00.

[2]. Diekmann O. dkk. 1990. On the Definition and the Computation of the Basic Reproduction Rasio $R_{0}$ in Models for Infectious Disease. J. Math. Biol. Vol 28: 365382.

[3]. Lindblade K.A. dkk,, 2013. The silent threat: asymptomatic parasitemia and malaria transmission, Expert Rev. Anti. Infect. Ther., 11(6), , p.623-639.

[4]. Kemenkes R.I., 2016. Eliminasi Malaria Indonesia, www.malaria.id, diakses tanggal 3 Mei 2018.

[5]. Traore Bakary, 2017. A Mathematical Model of Malaria Transmission with Structured Vektor Pupolation and Seasonality, DOI/10.1155/2017/6754097. 